\title{
pedagogías cuir y feminismos rapsódicos \\ en/desde valeria flores ${ }^{1}$
}

\author{
mariana alvarado ${ }^{2}$ \\ instituto de ciencias humanas, sociales y ambientales - conicet, argentina
}

\section{resumen}

Una premisa feminista anima a (des)nombrar ¿dónde es aquí? Un desde dónde que no se acota en predicar(le) a/de un sujeto un listado de adjetivos, modificadores o etiquetas de pertenencia; más que de una identidad carente de reconocimiento se trata del acontecer de un emplazamiento político. Posibilidades del decir que hacen que el hacer escuela, el recorrido de una investigación o las derivas de la militancia se vean radicalmente trastocadas. Presentamos las formas en las que el adscribir y el enunciar se anudan a los modos de hacer audibles y visibles como posicionamiento político individual y colectivo por dentro/fuera la escuela. Estas líneas acechan la posición nómade - de val flores - , la localización limitada y específica de un conocimiento situado, precario, itinerante que despliegan una pedagogía antinormativa, animada por una epistemología feminista descentrada del no saber y del no hacer; desde un feminismo under, microfeminismoo feminismo rapsódico disloca los regímenes de luz, de la modernidad en su encarnadura cartesiana, a los que pretendemos abrir(les) la puerta para jugar a probar. Expulsadas de la zona de concentración lumínica las ignorancias constituyen lo incognoscible, lo ininteligible, lo innominado, para las que se divisan al menos tres rutas: la memoria, el lenguaje, la afectividad.

palabras claves: punto de vista; posición de sujeto; conocimiento situado; disidencia; diversidad.

\section{queer pedagogy and rhapsodic feminisms in/from valeria flores}

\section{abstract}

A feminist premise encourages to (un)name where is here? A from of where that hasn't limit in preaching to/from the subject, in a list of adjectives, conditionals or in labels; more than an identity lacking in recognition, it is about the occurrence of a political location. It is about the possibilities of "saying" than can radically disrupt the starting of a movement, the journey of an investigation, or the drifts of militancy. We present here the ways in which "subscribing-to" or "stating" link to the ways of "making-audible and visible" as an individual or collective political standpoint, inside/outside the movement. These lines stalk the nomadic position - of val flores - , the limited and specific location of a situated, precarious, itinerant knowledge, which deploys an anti-regulatory pedagogy driven by a feminist epistemology, from an "under" feminism, animated by an offcentered feminist epistemology of not knowing and not doing. This is about a rhapsodic feminism that dislocates the regimes of light of modernity in its Cartesian embodiment to

\footnotetext{
${ }^{1}$ Este escrito es una deriva de indagación abierta en el PICT 1016-0590 (FONCyT-MINCyT) Feminismos del Sur. Experiencias y narrativas contemporáneas en la frontera academia/activismos que surge en las Jornadas de Filosofía y Educación (FFyL, UNCuyo, 2017) y se deja intervenir en el taller Incisiones poéticas feministas dictado por val flores en Mendoza a mediados de junio del 2018.

2 E-mail: elotro4to@gmail.com
} 
pedagogías cuir y feminismos rapsódicos en/desde valeria flores

play to prove. The ignorances expelled from the area of light concentration are integrated into the remains of the unknown, the unnamed, from there you can see at least three routes: memory, language, affections.

keywords: standpoint; subject position; situated knowledge; dissidence; diversity.

\section{pedagogias queer e feminismos rapsódicos em/a partir de valeria flores}

resumo

Uma premissa feminista anima a (des)nomear onde é aqui? Um onde que não se limita em predicar(lhe) a/de um sujeito uma lista de adjetivos, modificadores ou etiquetas de pertencimento; mais que de uma identidade carente de reconhecimento se trata do acontecer de uma localização política. Possibilidades do dizer que fazem que o fazer escola, o percurso de uma investigação ou as derivações da militância se encontrem radicalmente trocadas entre elas. Apresentamos as formas nas quais o subscrever e o enunciar se enrolam com os modos de fazer audíveis e visíveis como posicionamento político, individual e coletivo por dentro/fora da escola. Estas linhas perseguem a posição nômade - de val flores -, a localização limitada e específica de um conhecimento situado, precário, itinerante que se desdobra em uma pedagogia antinormativa, animada por uma epistemologia feminista descentrada do não saber e do não fazer; parte de um feminismo under, microfeminismo ou feminismo rapsódico desloca os regimes de luz, da modernidade em sua encarnação cartesiana, aos que pretendemos abrir(lhes) a porta para jogar e tentar. Expulsas da zona de concentração iluminada, as ignorâncias constituem o incognoscível, o ininteligível, o inominado, para as quais vemos ao menos três rotas: a memoria, a linguagem, a afetividade.

palavras-chave: ponto de vista; posição de sujeito; conhecimento situado; dissidência; diversidade. 
pedagogías cuir y feminismos rapsódicos

en/desde valeria flores ${ }^{3}$

politica de la situacionalidad

"la teoría es corporal, no es algo distante del cuerpo vivido; sino al contrario. La teoría es cualquier cosa menos desencarnada" DONNA HARAWAY, 1999

En la contratapa de uno de sus últimos facsímil se deja leer "escritora activista de la disidencia sexual tortillera feminista heterodoxa cuir masculina maestra prosexo vegana border de las instituciones" (FLORES, 2017); en su interior, a unas líneas de iniciar, "una maestra prófuga de la escuela y una activista sexual desertora de la política ortodoxa"; en una comunicación presentada en el Coloquio Latinoamericano sobre Pensamiento y praxis feminista hacia el 2009 se apunta "escritora feminista disidente sexual blanca tortillera trabajadora precarizada no madre habitante de una urbanidad periférica"; en la entrevista para la que Pilar Anastasía y Facundo Boccardi le convocan es presentada como "Activista lesbiana feminista queer masculina practicante de escrituras" (ANASTASÍA, BOCCARDI 2012, 213).

Ella, la post-fugitiva del desierto ${ }^{4}$, la otra, la maestra, la misma, la desertora de artículos, aquellx activista, ha querido ser nombrada como Valeria Flores y, aunque sus últimos textos fueron publicados como valeria flores, también se asoma como vale flores o se erosiona val flores. Recursos del des-nombre que alteran las jerarquías de la sintaxis y (des)autorizan las autorías sin desprenderse de aquello que instala la disidencia y arroja al malestar.

Una maestra que escribe un nombre propio en minúsculas, una maestra que

\footnotetext{
3 Este escrito es una deriva de indagación abierta en el PICT 1016-0590 (FONCyT-MINCyT) Feminismos del Sur. Experiencias y narrativas contemporáneas en la frontera academia/activismos que surge en las Jornadas de Filosofía y Educación (FFyL, UNCuyo, 2017) y se deja intervenir en el taller Incisiones poéticas feministas dictado por val flores en Mendoza a mediados de junio del 2018. 4 "Fugitivas del desierto" nombraba a un grupo de lesbianas feministas de la ciudad de Neuquén, Argentina, que activó desde el año 2004 hasta fines del 2008. Acuerpadas en un grupo de reflexión lésbica se propusieron pensar (en/desde) sus vidas el devenir lesbiana, la experiencia lesbiana y sus contextos: familia, amigos, calle, instituciones, además de leer y comentar textos de lesbianas feministas y lesbianas radicales moderando tiempos de escucha y de habla, dándo(se) la voz, autorizándo(se). La provocación de visibilizar(se) favoreció la permanencia en el grupo de aquellas que pudieron/quisieron asumir públicamente la identidad lésbica (Cfr. ANASTASÍA, BOCCARDI, 2012, 217-218).
} 
pedagogías cuir y feminismos rapsódicos en/desde valeria flores

dice un desde dónde, una maestra que escribe lo que dice frente a la exigencia de objetividad y neutralidad que atraviesan los procesos de escritura académica desde donde se pretende legitimar a quién, de qué modo y cómo se da cuenta -de manera impersonal y en la mayoría de los casos con el uso del plural masculinode ciertos conocimientos sobre experiencias de otras/os. Valeria Flores adscribe reapropiándose de una posición institucionalmente desvalorizada -no se considera el lugar de la maestra como un desde donde sea posible generar discurso legitimado sino, en todo caso como la autorizada para implementar, aplicar y adaptar o innovar con medianas licencias $\mathrm{y}$, a partir de lo sugerido o recomendado por técnicos especialistas, en casi todos los casos externos al sistema educativo-. Su posición reivindica un lugar, un desde, donde se producen saberes y desequilibra la maquinaria escolar que, ha puesto el saber por fuera del hacer docente, depotenciando su productividad, propiciando una mirada tecnocrática, despolitizando el trabajo pedagógico (ANASTASÍA, BOCCARDI 2012, 223).

Vive en La Plata, aunque su escritura se descentra de su residencia. Desde Neuquén traza la gramática para un juego que des-ordena las formas en las que los cuerpos son dichos, los modos en los que ciertos lugares han sido asignados, las referencias desde las que las prácticas han sido limitadas y los criterios a partir de los cuales los saberes han sido puestos en circulación, los permitidos que habilitan el acceso a ciertos placeres, dolores, penitencias. Contra el orden en el que las subjetividades son moduladas por las disciplinas del cuerpo y los discursos normativos, vuelve imposible la neutralización académica e identitaria en la búsqueda constante de referencias visuales, poéticas, vitales y colectivas.

Un modo de situarse en el cruce: sexo, género, clase, raza apertura la construcción de un locus. Un desde dónde que, sin embargo no se acota en predicar(le) a/de un sujeto un listado de adjetivos o etiquetas de pertenencia; más que de una identidad carente de reconocimiento se trata de un emplazamiento político que acontece; en todo caso como prótesis que denota un/a/x sujeto implicado en la materialidad de su existir, situada en coordenadas espaciales y discursivas que fisuran la heteronormatividad institucional. Constituyen para Haraway un posicionamiento-conocimiento-situado que permea la trayectoria de 
indagación modificando(nxs) ante lo que vemos y ante lo que nos mira (Cfr. HARAWAY, 1991, 326).

$\mathrm{Su}$ "yo", su "ella misma", su "sí misma" -si es que algo de eso pueda ser puesto a la vista, a la escucha, al olfato, al tacto, a la lengua- aparecen como trozos, escorzos, huellas, marcas de un adentro que se vuelve poroso en nombres múltiples, deseos, tiempos, haceres y mundos en la disputa de lo que (no/s) importa. Puesto que no da lo mismo devenir mujer, o trans o lesbiana siendo blanco o negra, o trabajadora rural o metalúrgico siendo social-demócrata o neoliberal viviendo en Dinamarca o en Jujuy, practicando el agnosticismo o declinando ante los pro-vida; no da lo mismo, (no) todos los cuerpos importan, cada uno ocupa una posición de sujetx en/desde la que se/nos esclaviza, daña, segrega, borra, oprime, mata 5 .

“¿Escritura lesbiana?, ¿escritura como lesbiana?, ¿escritura desde lesbiana?, ¿contra-escritura lesbiana?, ¿escritura en lesbiana? Entre retazos de lecturas, frases auscultadas al azar, anotaciones dispersas, interrogantes a medio formular, conexiones por experimentar, me apremia y compromete afirmarme lesbiana en este contexto neofascista y neoliberal que arrasa américa latina." (FLORES, 2017, 8)

Como lesbiana desde el sur entrama "el cuerpo de la letra con el cuerpo de la vida" y "el cuerpo del saber con el saber del cuerpo". Hace un uso político de las territorialidades, sin fijar una geografía: desde el territorio como en el cuerpo. Sur es una toma de posición, un lugar desde donde se alza la voz, una localización desde/para señalar como herramienta que desmantela la centralidad de los discursos occidentales y euro-norte-moderno-centrados y revertir la marginalidad

\footnotetext{
${ }^{5}$ Así, tampoco es lo mismo ser migrante a nómade por elección; ser trabajadora de la ciencia que académica institucionalizada. "La mujer" se deconstruye puesto que mujer/es les hay muchas: mujeres blancas, mujeres negras, mujeres que pertenecen a cierta clase social, las hay mujer lesbiana pero también lesbianas no-mujeres, mujeres cis y trans que se identifican como mujeres o como varones -aunque algunos a costa de adscribir como feministas reproduzcan estereotipos masculinos o femeninos tradicionales e, incluso sostengan estructuras opresivas sino violentas-. La particularidad de estas posiciones es que son posiciones desde/en/por las que se asignan funciones; según la posición de sujeta/o/x, la fuente de sustento, la experiencia de cada unx, se configura en el punto de vista que esos cuerpos encarnan y sostienen. Así Vale da cuenta del estallido de la identidad -de su cosificación o esencialización- desde las condiciones de producción de su escritura lesbiana visibilizando las condiciones materiales de la producción intelectual que atraviesa a muchas feministas, activistas, lesbianas proletarias no académicas (Cfr. FLORES, 2017, 20). Visibilizar tales condiciones da cuenta del sistema de producción de conocimiento científico así como de la/s (im)posibilidades de indagación y/o reflexión en la práctica docente que torna (in)viable las relaciones entre el saber académico y la des-academización del saber.
} 
pedagogías cuir y feminismos rapsódicos en/desde valeria flores

epistémica de las producciones locales incluso, rioplatenses puesto que en Argentina también hay un Norte.

"Somos la vieja guardia tortillera. Seremos viejas pero no domesticadas, no tenemos el pensamiento amansado ni nos arrebataron las palabras. Tortilleras es un nombre que no define nuestras vidas, sino que nos ubica políticamente. No describe con quién cogemos, nos posiciona en la escena pública para denunciar que nuestros cuerpos son un campo de batalla de las normas, las instituciones y las fuerzas represivas del estado, las iglesias, los medios y el mercado, que pretenden controlar nuestros deseos y nos dicen cómo debemos usar nuestros cuerpos para su beneficio." (CORBALÁN, FLORES, 2013)

Un espacio de autoafirmación -plural ahora, colectivo- que busca experimentar y visibilizar formas de ser en un hacer habitado por voces muchas, aquellas en las que quiere ser dicha, desde las que busca nombrarse, con las que experiencia los modos de la heterogeneidad y del movimiento, en las que se reconoce contradictoria, por las que se amaca disímil, otra cada vez en el tránsito, lo transitado y el transitar. Intentará amacar(se) (a)liada en su devenir a una "escritura de trapecio" (LUONGO, 2016) en la que corporiza su estar siendo al tiempo que se (des)marca en "producciones del shock" y "saberes de sobresalto"; un gesto que le lleva a escribir las prácticas como la forma de hacer teoría de un pensamiento contingente y situado:

"mis prácticas políticas como activista lesbiana y feminista queer, mis prácticas pedagógicas como maestra en una escuela donde la pobreza acecha con la muerte a los cuerpos de las chicas y los chicos, mis prácticas de escritura que colapsan con los modos habituales y más convencionales de la literatura, mis prácticas de pensamiento que se dislocan de las tradiciones e instituciones académicas de cuya legitimidad prescinden, reportando asimismo los costos de la falta de reconocimiento entre otras desautorizaciones, mis prácticas amorosas que sucumbían ante nuevas situaciones en que otros deseos irrumpían sin más, haciendo tajos en los modos del amor hasta el momento practicados, mis prácticas sexuales que fantaseaban con abrirse a la multiplicidad del goce que desterritorializara el placer sexual de la genitalidad." (FLORES, 2009)

Esa escritura visibiliza en las prácticas los modos de intevenir(nos) y (des)anda los discursos que nos armaron; esa escritura es un escribir contra-simisma pero también contra los totalitarismos, los universalismos, las abstracciones, los machismos, las épicas institucionales, las arrogancias 
intelectuales, el iluminismo militante, la civilización adoctrinadora, los binarismos fundantes, la moralina afectiva, el vocabulario unificador y la estabilidad identitaria. Esta política de la situacionalidad coloca a la escritura lesbiana como un punto de vista contra el no-where de la academia des-corporizada (ALVARADO, 2017, 39). val flores piensa ¿dónde es aquí? (2014) al tiempo que escribe el sujetx político del feminismo haciendo un uso político del género que estría a la sujeto del feminismo ${ }^{6}$

epistemologías feministas

El feminismo lesbiano ${ }^{7}$ de val flores, este feminismo under, mircrofeminismo o feminismo rapsódico, se monta en una epistemología descentrada, del no saber y del no hacer ${ }^{8}$.

Una epistemología descentrada del norte que, pensado como espacio de imposición de un centro del que todo emerge, se traduce en un desplazamiento hacia la localización discursiva por fuera como extrañamiento, renuncia y deserción que desquicia su constitución y normatividad. Inventa un sur, un desde aquí, en los modos de (des)organizar el norte ${ }^{9}$ como quiebres y/o desbordes.

Una epistemología del "no saber":

\footnotetext{
6 Si las lesbianas (no) son mujeres (Witting) ¿cuáles son los aportes del devenir lesbiana a los feminismos? Qué le adviene al feminismo si no decimos mujer. El feminismo puede también, ser una cadena como instrumento de normalización si se reduce a "la mujeres" y subsume en la neutralidad y universalidad a la multiplicidad de subjetividades en términos de raza, clase, sexualidad, edad, diferencias corporales, geopolíticas. Un denso silencio se expande en diversas y múltiples expresiones del género sancionadas con el distanciamiento, la invisibilización, el menosprecio, la subordinación, la reprobación tanto en sus formas masculinizadas como feminizadas. El automatismo "mujer" que les designa se des-arma cuando lesbiana se enseña como deserción de la repetición de roles, mandatos y procedimientos. En el feminismo los hay muchos; uno de ellos -no hegemónico, lúdico, creativo e irónico- el feminismo under, notifica de la rescisión del pacto heteropatriarcal.

${ }^{7}$ Con todos los cuidados que esta designación amerita puesto que, se hereda y traiciona a la vez; se marca y desanuda de los legados revolucionarios feministas, a las izquierdas, la disidencia sexual y el activismo lésbico.

8 Cercana, seguramente a la epistemología rumiante, devoradora, deglutora, regurgitadora como epistemología del no-consumo consumido de Lucrecia Masson (2017) cuyo método es lento, perezoso, poco productivo, poco sexy, grande, excesivo, de cuero muy duro, poco delicado para nada refinado, de andar lento y ocioso; mera resistencia a la velocidad y a la eficacia, al tiempo cronológico, lineal y medible; rompe con la lógica de la productividad; sin finales felices, ni metas consumadas, ni conclusiones estáticas.

9 Hacer un desde aquí dislocado implica pensar los procedimientos mediante los cuales (nos)hablamos/escribimos/subjetivamos al tiempo de reconstruir un archivo de insubordinaciones.
} 
"No sabemos lo que puede una escritura. No sabemos lo que puede una escritura desde el sur. No sabemos lo que puede una escritura lesbiana. Un ritual del no saber como desgarro de la complicidad con los modos presentes y dominantes del pensamiento de transparencia tecnomediática del mercado y el reglamentarismo de la legitimidad académica institucional, sin la pretensión arrogante de fundar una consigna, una teoría o un nombre propio, sino con el ánimo de explorar una posibilidad incierta (...)" (FLORES, 2017, 10)

Una epistemología del "no hacer":

"No hacer pedagogía para la escuela. No hacer arte para el museo. No hacer activismo para la política. No hacer performance para el espectáculo. No hacer rescrituras para el aplauso. No hacer memorias para el monumento. No hacer canon para la disidencia. No hacer nombre propio para el pensamiento colectivo. No hacer identidad para el estado. No hacer rebaños para los ídolos. No hacer romances para el amor. No hacer cuerpo para el capital. No hacer animales para la humanidad. No hacer comunidad para lealtades serviles. No hacer saberes para administrar destinos. No hacer yotuelnosotrosustedesellos para organizar fronteras. No hacer sur para una galería de víctimas. No hacer es un programa revolucionario." (GUAGLIANONE/FLORES, 2015)

Disloca los regímenes de luz de la epistemología moderna en su encarnadura cartesiana de transparencia y claridad en el acceso claro y distinto sin mediaciones (ALVARADO, 2017,46). Un régimen de luz que priorizó el ojo y la vista como órgano y sentido hegemónico en los regímenes disciplinares y de control. Pensar el otro lado la luz no implica permanecer a oscuras, en las sombras, del otro lado de lo iluminado sino más bien habitar un espacio otro: los excrementos de la luz, los desechos de la luminosidad omnisciente. Si el saber ha sido atado a la luz de la razón como producción de conocimiento, de subjetividad y normalidad su excremento deviene de lo que produce su propia ignorancia. Puesto que más que ocultar, más que dejar a oscuras, más que arrebatarle luminosidad, ha naturalizado las posibilidades de la visión y de lo por ser visto, de la percepción y de lo por percibir, de la interpretación y de lo por interpretar. Expulsados de la zona de concentración lumínica las ignorancias constituyen lo incognoscible, lo ininteligible, lo innominado.

La producción del saber científico como proyecto político se inscribe en ciertos intereses -sobre la vida, el lenguaje, los cuerpos, el amor, la sexualidad, las instituciones- capitalistas, neoliberales, patriarcales, heteroracializados, 
pretendidamente globales. Un tipo de conocimiento basado en pares binarios y dicotómicos que establecen clasificaciones, jerarquías y patologías funda en un sujeto hegemónico como parámetro de la normalidad: hombre/mujer; macho/hembra; masculino/femenino; heterosexual/homosexual; burgués/trabajador; blanco/negro; culto/ignorante; saber/opinión cuyo reflejo demarca dominar posiciones naturalizadas en espacios asignados público/privado; pensamiento/experiencia; ciencia/saber; un imaginario que (im)pone al varón como hombre, es decir, al particular como universal que subsume la diversidad, la diferencia, la disidencia. El imaginario moderno ilustrado puso al hombre como objeto universal, racional, abstracto, público sobre la mujer sujetada a la fantasía, los sentimientos, la intuición, las emociones, lo concreto, lo privado y al cuerpo anclado a la biología. Dos mundos se separan al tiempo que se complementan en su re-producción apareados en la heterocisnormatividad que re-produce el matrimonio, la familia y la maternidad obligatoria. Esta estructura del saber pone en movimiento prácticas cotidianas cuyos residuos se configuran en cada sujetx que escapa al orden de lo decible: negros, niños, pueblos originarios, gays, travestis, lesbianas, chongos, pobres, tortas, marimachos. La heteronormalidad discursiva promueve silencios e invisibilidades, ausencias y olvidos, así como pasión por la ignorancia (FLORES, 2013 , 43). La teoría feminista, los estudios lesbicos-gays y queer ${ }^{10}$ quieren instalar ciertas problematizaciones y cuestionamientos que tensan desde el ámbito epistemológico el sistema sexo/género en relación a expresión de género e identidad sexual cuyas interpelaciones impactan en la escuela y en el trabajo docente como pedagogías cuir antinormativas, en las académicas activistas y trabajadoras de la ciencia como epistemologías feministas y feminismos rapsódicos.

\section{hacer comunidad: acuerpando}

"Solo nos queda salir a errar por las tramas sensibles del saber, para crear autonomía relacional, afectiva e intelectual, una

\footnotetext{
10 Paul B. Preciado, Maerie-Helene/San-Burcier y Gracia Trujillo se encuentran en diálogos muy próximos. Transitar posibles articulaciones con las escrituras de val flores es un trabajo pendiente a transitar en próximos escritos.
} 
urdimbre interdependiente de voces y prácticas, con un vitalismo filosófico y una sabiduría del desapego que instigue a la composición de experiencia política, en la que la desilusión cumpla un papel activo" (FLORES, 2017, 17)

Con la lengua lesbiana11 aprendió a decir "yo" en primera persona del singular aunque amarrada, des-armada y en disputa a/con otras (des)habita un entre/sobre/contra-nosotras-juntas. Un aprendizaje que tiene lugar en un desde aquí y en entre/s movedizos, precarios e inestables en una comunidad políticaafectiva-artística:

"en las calles, en las aulas, en las camas, en las plazas, en las
montañas, en los mares, en los atardeceres de belleza nefanda y en
los amaneceres solitarios del viento; entre feministas, entre
mujeres, entre maricas, entre maestras y estudiantes, entre
travestis y varones trans, entre médicxs, entre poetas, entre
amigxs, entre enemigxs, entre libros, entre imágenes, entre
tiempos, entre mudanzas, entre secretos" (FLORES, 2017, 10)

Justo allí se hace/n lugar de paso y habitabilidad. Un pequeño mundo que les aloja provisoria y precariamente a la intemperie para escribirse lesbiana/s desde el sur "entre neuquén y buenos aires, argentina y también, entre lesbiana, escritora, maestra, feminista". Un hacer de otro modo que procede conectando y creando, en tránsito por, con y entre ${ }^{12}$.

pedagogías cuir

El gesto de val coloca a la docente, a la maestra como trabajadora de la cultura en cuanto posición política; agente de su propio saber y práctica; un modo de perturbar el orden, de mover la autoridad desde los técnicos o especialistas que dicen qué y cómo hacer a los docentes, descentrar la jerarquía del saber como práctica de autoafirmación política en/desde la disidencia sexual.

De las diversas posiciones de sujeta val puede/quiere ocupar posicion/es determinada/s: lesbiana, feminsita, docente, trabajadora, escritora, blanca, joven,

11 Para val flores caben muchos modos de escrituras pero al menos uno, el de la lengua lesbiana, adviene como práctica anticapitalisa, antipatriarcal, desheterosexualizante, antiracista y no binaria; refiere a una inscripción somática y (auto)biográfica, así, la escritura como un arte de re-educación corporal.

12 Desde "aquí" y "justo allí", por, con y entre, se visibiliza lesbiana sin conseciones, ni confesiones ni a solicitud de aprobación o permisos sino en la premura de un deseo que ha sido sistemáticamente negado; más que insistir en esencializar una identidad interviene políticamente y perfora la hetero cisnormatividad: efecto de cierto régimen de saber hegemónico. 
atea... de esas múltiples posiciones privilegia para hablar, para levantar la voz, para activar políticamente, para hacer escuela su sexualidad: lesbiana feminista. El hecho de anteponer la disidencia sexual es un gesto político que posicionándole en otro lugar -la docente como trabajadora intelectual y el trabajo pedagógico como intervención política- visibiliza la heteronormativiadad de las condiciones del trabajo docente.

El desafío se traduce en una pedagogía interrogativa que no quiere monopolizar la voz en la formulación de respuestas ${ }^{13}$ o en la naturalización de la voz masculina sino que dispone el espacio para que se articule la pregunta -desde la incomodidad, desde el malestar, con la denuncia, a partir del conflicto-.

La pedagogía de la maestra lesbiana ${ }^{14}$ no requiere de enseñar qué sea una persona trans, travesti o intersex sino más bien de desaprender las formas de pensamiento e interrogación heterocisnormativas; propicia que la palabra circule desde cada unx; apertura a la incorporación de voces de mujeres, pueblos originarios, LGBTTTIQ ${ }^{15}$ en la currícula -como temas o problemas pero también en la selección de textos en el listado de bibliografía- ya no como temas exóticos o excepciones sino como interrupciones al discurso logofaloeuronortecentrado en la mayoría de sus expresiones misóginos, sexistas para nada cuidadosos o amorosos; configura un desde dónde junto con otres entre el saber y el no-saber del/sobre el otro como enclave de la singularidad o determinación de identidad.

En la formulación de una pedagogía cuir se ponen en cuestión los marcos

\footnotetext{
${ }^{13}$ La posibilidad de otras pedagogías a venido acompañada para nosotras aquí en un desde donde situado en Nuestra América -que no ha podido aún, incorporar estas voces, estos tránstitos, estas derivas- en la Provincia de Mendoza de la mano del CIIFE (Centro de Investigaciones Interdisciplinarias en Filosofía y Educación) <http://ffyl.uncuyo.edu.ar/centro-deinvestigaciones-interdisciplinarias-de-filosofia-en-la-escuela-ciife $>$

$<$ http://www.filosofiayeducacion.uncu.edu.ar/presentacion> y en el marco de la Especialización en Filosofía con Niños y Jóvenes <http://ffyl.uncuyo.edu.ar/la-especializacion-en-filosofia-conninos-y-jovenes-reabre-las-inscripciones-para-cursar-su-segunda-cohorte>

${ }^{14}$ Lesbiana -como escape a la construcción patriarcal mujer- marca a la maestra como "fugitiva" exiliada voluntaria de la heterocisnormalidad, del dispositivo de feminización que encapsula a todas como mujeres por haber nacido con vulva y, asumiendo en esa biología ciertos rasgos del género femenino con el que "naturalmente" hemos de coincidir y que, nos lleva, anudadas a la heterosexualidad obligatoria, al matrimonio -como forma monogámica, complementaria y exclusiva del amor romántico- y la maternidad. Maestra lesbiana como itineranio en disputa contra la lesbofobia, el silencio y las formas de violencia e invisibilización institucionalizadas. Fugitivas como tránsito también como itinerarios en disputa.

${ }^{15}$ La sigla refiere a personas lesbianas, gays, bisexuales, transgénero, travestis, transexuales, intersexuales o queer.
} 
pedagogías cuir y feminismos rapsódicos en/desde valeria flores

de reconocimiento, identidad y legitimidad de lo que es considerado como humano y/o como sujetx de la educación en el propio nombrar/pensar/hacer que ponemos en juego revelando los intersticios diferentes, disidentes y aportando a desarrollar los lenguajes que hagan falta para desanclar el deseo de la unidireccionalidad normada.

No preguntar, no decir, no declarar ha sido la política que evita el conflicto en el ejercicio docente del hacer escuela heteronormativa. El saber interrogativo de una pedagogía cuir busca perforar el orden de las certezas naturalizadas y de las pruebas testeadas con el tajo especulativo de la sospecha, la conjetura, la invención y la poética. Si tuviera un inicio ese preguntar del que ya no podría seguir siendo la que era ni seguir diciendo lo que decía ni pensar lo que pensaba o hacer tal como lo hacía, habría de anclarse en las formas de escritura como balbuceos de lo que podría escribirse otra vez de nuevo de otro modo. Empezar a preguntar por las formas en las que decimos y los modos en los que escribimos lo que pensamos desarticula -en/con/desde Val- la posición de sujetx en una gramática de la disidencia sexo-política.

De allí que el uso político del género en el ámbito educativo potencie experiencias disidentes cuando el cuerpo interpela deconstruyendo binarismos. ¿Cuáles son las condiciones educativas que propician que ciertos cuerpos se construyan bajo/fuera/dentro/entre la norma? La escuela se empeña en garantizar que niñas/os se conviertan en hombres/mujeres que correspondan a la norma masculino/femenino. La heterocisnormatividad como conocimiento transversal y hegemónico opera de manera imperceptible en el aula construyendo normalidad como saber naturalizado mediante la producción de la expulsión en la ignorancia. ¿A qué nosotros le importa reiterar tales condiciones de producción? Sinembargo no todas las voces se expresan como nenes o nenas como chicos o chicas; no toda infancia (no) se adecua cada vez a parámetros binarios, insistir en que así sea, implica volver ininteligibles ciertos cuerpos. ¿Quién es ese nosotros que se desentiende de la invisibilización, del olvido, la ausencia, el silenciamiento? ¿Cuáles son las tácticas, las técnicas, las alianzas para tramitar la ansiedad que generan las interpelaciones devenidas de un otrx que porta una extrañeza difícil 
de asumir por la heterocisnorma? Valeria Flores (319) señala la terapéutica que anclada en la diversidad sexual, la integración de la diferencia y la diversidad sexo-afectiva vuelve al otrx anticipable, calculable y predecible.

\section{feminismos rapsódicos}

Visibilizar el locus de enunciación tramita los bordes de un nosotros y de algunos otrxs ¿quiénes de ellxs hablan y cuáles son hablados? ¿a quiénes escuchamos y por quiénes somos escuchadas? ¿por qué voces hablamos, qué voces habitan mi voz y en cuáles soy dicha? Disponer el espacio y habilitar la circulación de la palabra implica estar a la escucha. Un gesto que autoriza voces, relatos, testimonios, narrativas; una transformación en las prácticas vinculantes que trastoca las prácticas heteronormalizadoras en un acto de alejamiento del lugar que se tiene asignado en un orden. Si la posición de sujetx delimita posibilidades para el decir, el pensar, el hacer y, también para el escuchar, el acto con el cual se desarma la configuración de los lugares asignados desfonda los modos del ver, del nombrar, del hacer. Una lejanía de sí, contra sí, ahora, aquí entre nosotres.

Valeria Flores traza huellas para un feminismo subterráneo en la disputa por otros modos de hacer y vincular vida política-afectiva-artística. El primer tránsito lo esboza en la memoria ¿cómo re-leemos nuestros archivos de la disidencia? Instala la pregunta en el cruce de la novedad y la contigencia, de lo nuevo y lo efímero. ¿Con qué trozos de voces, cuerpos, saberes, experiencias, discursos y acciones nos (des)hacemos o hicismos activistas de la disidencia? ¿Cómo las experiencias del pasado del movimiento LGBTTTIQ interpelan la coyuntura? Antepongo a sus preguntas algunas otras: ¿cuáles son nuestros archivos? ¿cuál es la disidencia sobre la que se construyen? ¿cuáles son las claves de lectura para re-leer un archivo disidente? ¿cómo se articula un hacer teoría del/desde el activismo feminista, el movimiento de mujeres, desde el LGBTTTIQ? ¿cómo configuramos un archivo que augura desmarcarse del canon por fuera de la casa del amo? ¿cuáles son los formatos en los que hace cuerpo una memoria batallante e incómoda? El segundo transitar anticipa la capacidad de inventiva de un vocabulario político que despoja y/o coloniza experiencias tortas, trans, 
pedagogías cuir y feminismos rapsódicos en/desde valeria flores

lésbicas, intersex, maricas en las políticas del nombre propio. La diversidad desnombra las identididaes LGBTTTIQ, desplazando la discusión por la norma evita el pensamiento crítico como localización y tratamiento del conflicto y se inscribe en la construcción de un escenario armónico en el que predica la compasión, la tolerancia, el respeto y la simpatía. ¿Cómo se articula la diferencia en la disidencia de los léxicos sexo-políticos? ¿En qué contextos circula esa articulación y qué tipo de (des)articulaciones produce? Valeria Flores entiende que la disidencia, en cuanto cuestionamiento práctico, es la única forma posible de hablar de las sexualidades y géneros no heternormativos que desactiva el imperialismo del paradigma epistémico político de lo diverso. La tercera ruta se expande en la afectividad y en los modos de restituir y reconstruir las condiciones emocionales de encontrarnos acuerpadas. ¿Cómo potenciar la capacidad de afectar y ser afectadas? ¿De abrir y aperturar territorios? ¿De explorar territorialidades sin invadir ni colonizar, sin depender ni sujetar?

\section{bibliografía}

ALVARADO, M. "Interrupciones en Nuestra América con voz de mujer" en: Alvarado, Mariana y Alejandro De Oto (Edit.). Metodologías en contexto. Intervenciones en perspectiva feminista, poscolonial, latinoamericana. Buenos Aires, CLACSO, 2017. 34-48. ANASTASÍA, P. y BOCCARDI, F. "valeria flores. Acciones que contaminan lo estético y lo político" en: VVAA Itinerarios de la transgresión. Polítias, sujetos y experiencias. Córdoba, Comunicarte, 2012. 213-231.

BRITZMAN, D. "Educación precoz" En: TALBURT, S. y STEINBERG, S.R. (eds) (2005). Pensando queer. Sexualidad, cultura y educación. Barcelona, Graó, 2005. 51-75.

CORBALÁN, M. y FLORES, V. "Tantas veces" leído en el "Pepazo a la lesbofobia" organizado por Diversidad de Río Negro y Neuquén y Sin Cautivas (Neuquén), 7 de marzo de 2013. Última vez consultado: 26/06/2018 Disponible en: <http:/ / escritoshereticos.blogspot.com.ar/2013/03/tantas-veces.html>

FLORES, V. "los cuerpos que (no) imaginamos. Lengua, poder y educación" Conversatorio. Escuelas de Ciencias de la Educación, Escuela de Historia. Facultad de Humanidades y Artes. UNR. Área de género, mujeres y diversidad sexual de COAD. Rosario, 15 de julio de 2018.

FLORES, V. Una poética feminista disidente. Éxtasis, perturbación e ironía. La Plata, POPOVA, 2017.

FLORES, V. La intimidad del procedimiento. Escritura, lesbiana, sur como prácticas de sí. La Plata, POPOVA, 2017.

FLORES, V. "Con los excrementos de la luz Interrogantes para una insurgencia sexopolítica disidente". Panel: Legislaciones estatales y disidencias sexuales. Repensando las esferas de lucha de los movimientos sociosexuales. 7mo Foro Nacional de Educación para el Cambio Social- ENEOB (Espacio Nacional de estudiantes de Organizaciones de Base) Córdoba (setiembre, 2015). 
FLORES, V. ¿dónde es aquí? Córdoba, bocavulvaria ediciones, 2014.

FLORES, V. "Secretos y silencios. La ignorancia como política de conocimiento y práctica de hetero(normalización)" en: Revista de trabajo social. Academia, la voz de los expertos. Nro 18. 2008.

GUAGLIANONE, F. y FLORES, V. Colaboración para Agenda Kuir, Chile, 2016. Disponible en <http://agendakuir.blogspot.com.ar/2014/12/2015.html> Última consulta: 26/6/2018

HARAWAY, D. Simians, Cyborgs and Women: The Reinvention of Nature New York: Routledge, and London: Free Association Books, 1991.

MASSON, L. Epistemología rumiante. 2017. Disponible en: <https:/ / issuu.com/pensarecartoneras/docs/rumiante> Última consulta: 2/7/2018

LUONGO, G. "Pedro Lemebel: Trapecio de una escritua" en: Nomadías. Chile, Julio 2016, $\mathrm{n}^{\circ} 21,191-234$. 